\title{
ANÁLISE DA PRODUCְÃO CIENTÍFICA SOBRE DOENÇAS SEXUALMENTE TRANSMISSÍVEIS E SUA RELAÇÃO COM A SAÚDE ESCOLAR NO BRASIL
}

\author{
Bruno Del Sarto Azevedo" \\ Camila Calhau Andrade Reis" \\ Kleyton Trindade Santos"* \\ Ana Cristina Santos Duarte *** \\ Rita Narriman Silva de Oliveira Boery ****
}

RESUMO: Revisão integrativa que objetivou identificar o que a literatura científica tem abordado acerca das doenças sexualmente transmissíveis relacionado ao escolar da educação básica no Brasil. A investigação ocorreu por meio de acesso à Biblioteca Virtual em Saúde, utilizando os descritores "doenças sexualmente transmissíveis", "saúde escolar" e “educação sexual", entre os anos de 2003 a 2012, tendo sido selecionados oito estudos. Os resultados evidenciaram que o tema, apesar de bastante difundido no âmbito escolar, está pouco esclarecido para os jovens escolares, principalmente no que concerne ao entendimento sobre a transmissão e contaminação. A escola tem o dever de orientar e direcionar os alunos para uma prática preventiva, por meio de programas educacionais e abordagem correta. Conclui-se que há necessidade de capacitação dos profissionais, seguida de incremento dos estudos, a fim de que estratégias sejam desenvolvidas no intuito de melhorar a educação e a saúde, algo indissociável e indispensável em qualquer população.

Palavras-chave: Doenças Sexualmente Transmissíveis. Saúde Escolar. Educação Sexual.

\footnotetext{
* Mestrando em Enfermagem e Saúde pela Universidade Estadual do Sudoeste da Bahia (UESB). E-mail: brunodelsarto@outlook.com

** Mestranda em Enfermagem e Saúde pela Universidade Estadual do Sudoeste da Bahia (UESB). E-mail: mila_calhau@hotmail.com

*** Mestrando em Enfermagem e Saúde pela Universidade Estadual do Sudoeste da Bahia (UESB). E-mail: kleyton_santos@hotmail.com

*** Pós-doutora em Didática das Ciências Experimentais pela Universidad Nacional del Litoral (UNL). Professora Titular do Departamento de Ciências Biológicas, do Programa de Pós-Graduação em Enfermagem e Saúde e do Programa de Pós-Graduação em Educação Científica e Formação de Professores da Universidade Estadual do Sudoeste da Bahia (UESB). E-mail: tinaduarte2@gmail.com

***** Pós-doutora em Bioética pela Universidade Católica Portuguesa (UCP); Professora Titular do Departamento de Saúde II e do Programa de Pós-Graduação em Enfermagem e Saúde da Universidade Estadual do Sudoeste da Bahia (UESB). E-mail: rboery@gmail.com
} 


\section{SCIENTIFIC ANALYSIS PRODUCTION REGARDING SEXUALLY TRANSMITTED DISEASES AND ITS RELATIONSHIP TO SCHOOL HEALTH IN BRAZIL}

ABSTRACT: This integrative review aimed to identify the scientific literature approaching about sexually transmitted diseases related to basic education students in Brazil. The investigation consisted in accessing the Virtual Health Library, by using the descriptors "sexually transmitted diseases", "school health" and "sex education", between the years 2003 and 2012, arising from the selection of eight studies. The results showed that the issue, although widely discussed in schools, is poorly understood by young students, especially regarding to transmission forms and contamination. Schools are responsible for guiding and directing students to preventive practice, through educational programs and correct approaching. The necessity for professional training, followed by studies increasing were concluded, therefore, strategies should be developed in order to improve education and health, a most importantly matter deeply rooted and imperative to any population.

Keywords: Sexually Transmitted Diseases. School Health. Sex Education.

\section{INTRODUĈ̣̃O}

A partir das transformações ocorridas nas relações de gênero e de domínio, sobretudo com a ascensão e independência feminina, associadas aos avanços nas pesquisas, a questão da sexualidade ganhou maior proporção nos cenários de discussão e sua construção passou a se dar de forma continuada e infindável (LOURO, 2008).

Antes envolta por tradições religiosas, a abordagem da sexualidade passou a alcançar novos horizontes, à medida que profissionais de diferentes áreas passaram a estudare atuarnos aspectos teóricos e práticos relacionados ao tema. Inclui-se, logicamente, a discussão referente às práticas sexuais e suas repercussões em diferentes grupos populacionais. Assim, a epidemiologia e os problemas provenientes de tais práticas, atrelados ao modo como cada sociedade encara a questão sexual, assumiram papel de destaque não só nas políticas sociais e populacionais, como também no âmbito da atenção à saúde, principalmente com o avanço das doenças sexualmente transmissíveis (DSTs) (PAIVA, 2008).

As DSTs readquiriram importância como problema de saúde pública mundial após a epidemia de AIDS, uma vez que 
pessoas com DST têm um risco aumentado de se infectar pelo HIV, risco este que aumenta ainda mais se a doença cursa com úlceras genitais (BRASIL, 2006b).

A Organização Mundial de Saúde estima que 333 milhões de casos de DSTs curáveis ocorram a cada ano, sendo mais de dois terços em países em desenvolvimento (DEHNE; RIEDNER, 2005). Outros tantos milhões de DSTs não curáveis, incluindo o herpes genital (HSV-2), infecções pelo vírus do papiloma humano (HPV) e infecção pelo HIV também ocorrem anualmente (WHO, 2005). Acredita-se que a maior parte dessas infecções se dê em pessoas com menos de 25 anos de idade, com as maiores taxas sendo frequentemente observadas entre a faixa etária de 20 a 24 anos, seguida pela faixa etária de 15 a 19 anos (DEHNE; RIEDNER, 2005).

No Brasil, foram notificados, do período que vai de 1980 a junho de 2012, 72.161 casos de AIDS entre jovens, sendo 14.724 (20,4\%) entre a faixa etária de 10 e 19 anos (BRASIL, 2012). Já os dados sobre a prevalência de outras DSTs entre a população jovem brasileira são insuficientes. Contudo, as tendências gerais apontam para uma maior prevalência de herpes genital e HPV, com 17\% e 25\% dos casos registrados na faixa dos 10 a 24 anos, respectivamente (BRASIL, 2006a).

Os elevados índices dessas doenças entre a juventude e adolescência brasileira ratificam importantes intervenções no campo da saúde sexual e reprodutiva, tanto no plano da prevenção e promoção da saúde, como no da assistência propriamente dita (BRASIL, 2006a).

Nesse contexto histórico, em 2003, é lançado o projeto Saúde e Prevenção nas Escolas (SPE), resultado da parceria entre o Ministério da Saúde, o Ministério da Educação, a Organização das Nações Unidas para a Educação, a Ciência e a Cultura (United Nations Educational, Scientific and Cultural Organization - UNESCO) e o Fundo das Nações Unidas para a Infância (United Nations Children's Fund - UNICEF) (BRASIL, 2006a).

O SPE vem com o intuito de reduzir a vulnerabilidade dos adolescentes e jovens às DSTs, à infecção pelo HIV e à gravidez não planejada, com ênfase na promoção da saúde, por meio de ações educativas de prevenção e ampliação do acesso dessa população ao preservativo masculino. Nesta perspectiva, o projeto pretendeu reforçar a qualificação e a formação continuada de professores nessa temática, prevendo disponibilização de preservativos masculinos a adolescentes e jovens de 13 a 24 anos, matriculados no ensino fundamental e médio da rede pública (BRASIL, 2006a). 
Em 5 de dezembro de 2007, também no âmbito dos Ministérios da Educação e da Saúde, é instituído o Programa Saúde na Escola (PSE), que se articula ao SPE, potencializando-o. Ele tem como finalidade contribuir para a formação integral dos estudantes da rede pública de educação básica, por meio de ações de prevenção, promoção e atenção à saúde, a partir da integração e articulação permanente entre as políticas e ações de educação e de saúde, com a participação da comunidade escolar, envolvendo as equipes de saúde da família e da educação básica (BRASIL, 2007).

Dentre seus objetivos, está o de promover a saúde e a cultura da paz, a partir de ações em saúde que considerarão a atenção, promoção, prevenção e assistência à saúde, compreendendo, entre outras ações, a de promoção da saúde sexual e reprodutiva, diretamente relacionada à questão das doenças sexualmente transmissíveis (BRASIL, 2007).

Desse modo, o presente estudo buscou identificar o que a literatura científica tem abordado acerca das doenças sexualmente transmissíveis, relacionado ao escolar da rede pública de educação básica no Brasil. Este trabalho de revisão visa contribuir para a reflexão sobre a importância da educação em saúde em relação às DSTs para esses estudantes, observando as possíveis melhorias a partir da adoção efetiva do PSE.

\section{MÉTODOS}

Trata-se de uma revisão integrativa que busca elucidar a questão: "o que a literatura científica tem abordado acerca das doenças sexualmente transmissíveis relacionado ao escolar da rede pública de educação básica no Brasil?’. Este método tem por finalidade reunir e sintetizar resultados de pesquisas sobre um delimitado tema, de forma sistemática e ordenada, contribuindo para o entendimento aprofundado a esse respeito (MENDES; SILVEIRA; GALVÃO, 2008).

Para o desenvolvimento do estudo, foram seguidas as seis etapas características para construção de uma revisão integrativa, propostas por Mendes, Silveira e Galvão (2008): 1) identificação do tema ou questão de pesquisa; 2) estabelecimento de critérios para inclusão e exclusão de estudos; 3) definição das informações a ser extraídas dos estudos selecionados; 4) avaliação dos estudos incluídos; 5) interpretação dos resultados; e 6) apresentação da revisão.

A investigação exploratória ocorreu em março de 2013, por meio de consulta à Biblioteca Virtual em Saúde (BVS). Os termos 
utilizados para a busca, selecionados a partir dos Descritores em Ciências da Saúde (DeCS), da Literatura Latino-Americana e do Caribe em Ciências da Saúde (LILACS), foram "doenças sexualmente transmissíveis", "saúde escolar" e "educação sexual", dando-se o rastreamento pela utilização do operador booleano "OR" entre os descritores supracitados.

Foram estabelecidos como critérios de inclusão: ser documento do tipo artigo científico, com disponibilidade de texto completo; ter como assunto a realidade do Brasil; ter sido publicado entre os anos de 2003 e 2012; e abordar, de forma central, a temática das doenças sexualmente transmissíveis relacionadas à saúde escolar de estudantes da rede pública de educação básica. Artigos que respeitaram tais critérios, mesmo que tenham investigado a temática entre alunos da rede privada (conjuntamente com os da rede pública), também foram incluídos nesta revisão, embora somente os resultados referentes aos estudantes de escolas públicas tenham sido considerados para discussão.

A restrição efetuada à área geográfica justifica-se pela necessidade de traçar um panorama sobre a produção de conhecimentos acerca da temática pesquisada, a partir da instauração do SPE no país. Por essa razão, anos anteriores a 2003 não foram levados em consideração, uma vez que o projeto foi instituído somente nesse ano.

Tal busca identificou um total de 267 artigos, nos quais foi realizada leitura criteriosa dos títulos pelos autores deste manuscrito, selecionando, assim, 38 artigos científicos. Estes, por sua vez, tiveram seus resumos lidos na íntegra e passaram por uma leitura flutuante de todo o corpo do estudo, a fim de identificar quais abordavam, de forma central, a temática estudada e que, dessa forma, atendiam aos critérios de inclusão do presente estudo. Ao final desta etapa, foram selecionados oito artigos, julgados coerentes com a proposta desta revisão.

Tais estudos tiveram seus textos lidos por completo; foi realizada a caracterização e o fichamento desses estudos, de modo a compilar, dentre outras variáveis: título do artigo, identificação dos autores e do periódico, ano de publicação, objetivo, população do estudo, bem como os principais resultados e conclusões. A partir dá, procedeuse à avaliação dos estudos e interpretação dos resultados, os quais foram sintetizados e organizados, de modo a orientar a discussão.

A Figura 1 apresenta os principais elementos do delineamento metodológico desta revisão integrativa, no que se refere à busca e à análise crítica dos artigos. 
FIGURA 1 - Representação esquemática do delineamento do estudo. Jequié-BA, Brasil, 2013.

Busca eletrônica na Biblioteca Virtual em Saúde (MEDLINE, LILACS, BDENF)

Descritores: "Doenças Sexualmente Transmissíveis", "Educação Sexual”, "Saúde Escolar"

Identificação de 267 artigos científicos

Análise de título

Seleção de 38 publicações científicas

Análise de resumo e leitura flutuante do corpo do artigo

\section{Seleção final de 8 estudos}

\section{RESULTADOS}

Dos oito artigos selecionados, todos encontravam-se presentes no LILACS, repetindo-se quatro no Medical Literature Analysis and Retrieval System Online (MEDLINE) e dois na Base de Dados de Enfermagem (BDENF).

Observando o ano de publicação dos artigos, percebeu-se que dois foram publicados em 2011, restando um artigo para cada ano a 
seguir: 2010, 2009, 2007, 2006, 2005 e 2003. Nenhum dos 43 autores esteve presente repetidamente em mais de um artigo, e apenas os periódicos Revista Enfermagem UERJ e Cadernos de Saúde Pública tiveram, cada um, dois artigos selecionados de seus acervos.

No que diz respeito à formação dos autores, dezoito $(41,8 \%)$ são médicos, treze (30,4\%) enfermeiros, dois (4,7\%) sociólogos, um (2,3\%) estatístico, um (2,3\%) psicólogo, um (2,3\%) nutricionista, um $(2,3 \%)$ pedagogo, um (2,3\%) jornalista, um (2,3\%) cientista social, um $(2,3 \%)$ acadêmico de medicina, um (2,3\%) acadêmico de enfermagem e dois (4,7\%) não identificados. No que se refere à titulação, cinco $(11,6 \%)$ são livres-docentes, três $(7,0 \%)$ são pós-doutores, dezoito (41,8\%) doutores, cinco (11,6\%) mestres, cinco $(11,6 \%)$ especialistas, dois $(4,7 \%)$ graduados, dois $(4,7 \%)$ graduandos e três $(7,0 \%)$ não foram identificados.

Entre esses pesquisadores, 28 declararam-se diretamente vinculados a alguma instituição de ensino superior, à época das publicações. Destes, oito $(28,6 \%)$ procedem da Universidade Federal do Ceará, seis $(21,4 \%)$ do Instituto Fernandes Figueira, quatro $(14,3 \%)$ da Universidade Gama Filho, três $(10,7 \%)$ da Universidade Estadual de Campinas, dois (7,1\%) da Universidade Federal de Goiás, dois $(7,1 \%)$ da Pontifícia Universidade Católica de Goiás, um (3,6\%) da Universidade Federal do Rio de Janeiro, um $(3,6 \%)$ da Fundação Técnico-Educacional Souza Marques e um (3,6\%) da Universidade Federal de São Paulo.

São três as abordagens temáticas principais utilizadas pelos estudos selecionados, no que diz respeito à questão das doenças sexualmente transmissíveis e saúde escolar no Brasil. Dessa forma, cinco dos artigos abordaram as concepções - conhecimentos e/ou crenças em relação a formas de transmissão e prevenção, cura, contatos casuais e fatores de risco - dos estudantes sobre as DSTs; três artigos enfocaram os efeitos de ações de educação em saúde sobre DST junto à escola; e dois estudos, concomitantemente à investigação sobre as concepções dos escolares, analisaram os fatores associados ao conhecimento e/ou formas de prevenção das DSTs.

As demais informações e a síntese dos resultados e conclusões dos artigos encontram-se presentes no QUADRO 1 abaixo. 
QUADRO 1 - Referência, objetivo, principais resultados e conclusões dos artigos selecionados do estudo. Jequié-BA, Brasil, 2013.

\begin{tabular}{|c|c|c|c|}
\hline $\mathrm{N}^{0}$ & Referência & Objetivo & $\begin{array}{l}\text { Principais resultados e } \\
\text { conclusões }\end{array}$ \\
\hline 1. & $\begin{array}{l}\text { MALTA, D. C. et } \\
\text { al. Orientaç̃os de } \\
\text { saúde reprodutiva } \\
\text { recebidas na escola } \\
\text { - uma análise da } \\
\text { Pesquisa Nacional de } \\
\text { Saúde do Escolar nas } \\
\text { capitais brasileiras e } \\
\text { no Distrito Federal, } \\
\text { 2009. Epidemiol. } \\
\text { Serv. Saúde, Brasília, } \\
\text { v. 20, n. 4, dez. 2011. }\end{array}$ & $\begin{array}{l}\text { Descrever as } \\
\text { orientações recebidas } \\
\text { pelos adolescentes na } \\
\text { escola quanto à saúde } \\
\text { sexual, DST/AIDS, } \\
\text { prevenção de gravidez } \\
\text { e aquisição gratuita } \\
\text { de preservativos a } \\
\text { partir da Pesquisa } \\
\text { Nacional de Saúde do } \\
\text { Escolar. }\end{array}$ & $\begin{array}{l}\text { - 89,4\% dos alunos das escolas } \\
\text { privadas e } 87,5 \% \text { das escolas públicas } \\
\text { relataram ter recebido orientação na } \\
\text { escola sobre DST. } \\
\text { - Com relação à informação sobre a } \\
\text { aquisição gratuita de preservativo, } \\
\text { a maior frequência foi em escolas } \\
\text { públicas. } \\
\text { - Constatou-se que o tema tem sido } \\
\text { abordado nas escolas, podendo } \\
\text { contribuir para a mudança de } \\
\text { comportamentos relacionados à } \\
\text { sexualidade. }\end{array}$ \\
\hline 2. & $\begin{array}{l}\text { COELHO, R. F. S. et } \\
\text { al. Conhecimentos } \\
\text { e crenças sobre } \\
\text { doenças sexualmente } \\
\text { transmissíveis e } \\
\text { HIV/AIDS entre } \\
\text { adolescentes e jovens } \\
\text { de escolas públicas } \\
\text { estaduais da região } \\
\text { oeste de Goiânia. Rev. } \\
\text { Patol. Trop., Goiânia, } \\
\text { v. } 40, \text { n. 1, jan.-mar. } \\
2011 .\end{array}$ & $\begin{array}{l}\text { Investigar os } \\
\text { conhecimentos e as } \\
\text { crenças sobre DST/ } \\
\text { HIV/AIDS entre } \\
\text { adolescentes e jovens } \\
\text { de } 15 \text { a } 24 \text { anos dos } \\
\text { sexos masculino e } \\
\text { feminino da Rede } \\
\text { Pública Estadual de } \\
\text { Ensino, inseridos em } \\
\text { escolas da região } \\
\text { oeste de Goiânia, e } \\
\text { identificar possíveis } \\
\text { diferenças de gênero. }\end{array}$ & $\begin{array}{l}\text { - Os dados evidenciam uma média de } \\
\text { conhecimento de } 77 \% \text { em relação à } \\
\text { AIDS e, no que se refere às outras } \\
\text { DSTs, a média foi maior para o sexo } \\
\text { feminino. } \\
\text { - Pode-se afirmar que o conhecimento } \\
\text { obtido pelos adolescentes e jovens } \\
\text { de ambos os sexos sobre DST/AIDS é } \\
\text { insatisfatório e que persistem crenças } \\
\text { errôneas que os expõem a riscos para } \\
\text { AIDS e outras DSTs. }\end{array}$ \\
\hline 3. & $\begin{array}{l}\text { DIAS, F. L. A. } \\
\text { et al. Riscos e } \\
\text { vulnerabilidades } \\
\text { relacionados à } \\
\text { sexualidade na } \\
\text { adolescência. } \\
\text { Rev. enferm. UERJ, } \\
\text { Rio de Janeiro, v. 18, } \\
\text { n. 3, jul.-set. 2010. }\end{array}$ & $\begin{array}{l}\text { Relatar os efeitos das } \\
\text { aç̃os de educação } \\
\text { em saúde junto à } \\
\text { escola, que visaram à } \\
\text { conscientização dos } \\
\text { adolescentes acerca } \\
\text { da realização de } \\
\text { medidas preventivas } \\
\text { para DSTs e gravidez } \\
\text { não planejada. }\end{array}$ & $\begin{array}{l}\text { - Os adolescentes conhecem o } \\
\text { preservativo masculino, mas não } \\
\text { o utilizam de maneira correta e } \\
\text { sistemática, expondo-se às DST/AIDS e } \\
\text { à gravidez. } \\
\text { - As estratégias de educação em } \\
\text { saúde devem ser direcionadas para } \\
\text { os adolescentes com a finalidade } \\
\text { de propiciar a reflexão crítica dos } \\
\text { alunos sobre as questões de risco } \\
\text { e vulnerabilidades relacionadas ao } \\
\text { comportamento sexual. }\end{array}$ \\
\hline
\end{tabular}




\begin{tabular}{|c|c|c|c|}
\hline $\mathbf{N}^{0}$ & Referência & Objetivo & $\begin{array}{c}\text { Principais resultados e } \\
\text { conclusões }\end{array}$ \\
\hline 4. & $\begin{array}{l}\text { FERNANDES, J. F. P. } \\
\text { et al. Conhecimento } \\
\text { de alunos deficientes } \\
\text { auditivos e de } \\
\text { seus educadores } \\
\text { relacionado às } \\
\text { doenças sexualmente } \\
\text { transmissíveis. Rev. } \\
\text { enferm. UERJ, Rio de } \\
\text { Janeiro, v. 17, n. 3, } \\
\text { jul.-set. 2009. }\end{array}$ & $\begin{array}{l}\text { Identificar, no grupo } \\
\text { de alunos deficientes } \\
\text { auditivos e no grupo } \\
\text { de seus educadores, } \\
\text { o conhecimento sobre } \\
\text { DST. }\end{array}$ & $\begin{array}{l}\text { - No grupo dos alunos deficientes } \\
\text { auditivos, apenas } 8 \text { ( } 40 \%) \text { conheciam } \\
\text { as DSTs. } \\
\text { - A escola apareceu na } 3^{\text {a }} \text { colocação } \\
\text { para acesso de informação sobre DST. } \\
\text { - Foi observado que os surdos vivem em } \\
\text { condição de risco para contrair DST. }\end{array}$ \\
\hline 5. & $\begin{array}{l}\text { ROMERO, K. T. et al. } \\
0 \text { conhecimento das } \\
\text { adolescentes sobre } \\
\text { questões relacionadas } \\
\text { ao sexo. Rev. Assoc. } \\
\text { Med. Bras., São } \\
\text { Paulo, v. 53, n. 1, fev. } \\
2007 .\end{array}$ & $\begin{array}{l}\text { Avaliar } 0 \\
\text { conhecimento das } \\
\text { adolescentes sobre } \\
\text { sexualidade, métodos } \\
\text { contraceptivos e } \\
\text { DST em uma escola } \\
\text { pública, da cidade } \\
\text { de Guararema, } \\
\text { São Paulo, para } \\
\text { construção de } \\
\text { um programa de } \\
\text { saúde integral ao } \\
\text { adolescente na rede } \\
\text { escolar na cidade. }\end{array}$ & $\begin{array}{l}\text { - As jovens da zona rural buscaram } \\
\text { mais informaç̃̃es sobre a sexualidade } \\
(81,2 \%) \text {, comparadas com as da zona } \\
\text { urbana }(72,2 \%) \text {, e a principal fonte de } \\
\text { informação foram os pais nas duas } \\
\text { regiões. } \\
\text { - A camisinha foi o método } \\
\text { contraceptivo mais conhecido pelas } \\
\text { adolescentes em ambas as áreas. A } \\
\text { AIDS é a DST mais conhecida nos dois } \\
\text { grupos. } \\
\text { - A maioria das adolescentes buscou } \\
\text { informações sobre sexualidade, } \\
\text { mas os conhecimentos sobre DST e } \\
\text { contracepção são inadequados. }\end{array}$ \\
\hline 6. & $\begin{array}{l}\text { MARTINS, L. B. M. et } \\
\text { al. Fatores associados } \\
\text { ao uso de preservativo } \\
\text { masculino e ao } \\
\text { conhecimento } \\
\text { sobre DST/AIDS } \\
\text { em adolescentes de } \\
\text { escolas públicas e } \\
\text { privadas do Município } \\
\text { de São Paulo, Brasil. } \\
\text { Cad. Saúde Pública, } \\
\text { Rio de Janeiro, v. 22, } \\
\text { n. 2, fev. 2006. }\end{array}$ & $\begin{array}{l}\text { Comparar o } \\
\text { conhecimento sobre } \\
\text { DST/AIDS e avaliar } \\
\text { os fatores associados } \\
\text { ao conhecimento } \\
\text { adequado e ao } \\
\text { uso consistente } \\
\text { do preservativo } \\
\text { masculino, em } \\
\text { adolescentes de } \\
\text { escolas públicas e } \\
\text { privadas do Município } \\
\text { de São Paulo, Brasil. }\end{array}$ & $\begin{array}{l}\text { - } 0 \text { uso consistente de preservativo } \\
\text { foi de } 60 \% \text { nas escolas privadas e de } \\
57,1 \% \text { nas públicas e esteve associado } \\
\text { ao sexo masculino e menor nível } \\
\text { socioeconômico. } \\
\text { - O sexo feminino, maior escolaridade, } \\
\text { escola privada, cor branca e estado } \\
\text { marital solteiro associaram-se ao maior } \\
\text { conhecimento sobre DST. } \\
\text { - Os adolescentes de escola pública } \\
\text { e privada apresentam conhecimento } \\
\text { adequado sobre prevenção de DST, } \\
\text { entretanto esse conhecimento não } \\
\text { determina adoção de atitudes efetivas } \\
\text { de prevenção. }\end{array}$ \\
\hline
\end{tabular}




\begin{tabular}{|c|c|c|c|}
\hline $\mathbf{N}^{0}$ & Referência & Objetivo & $\begin{array}{l}\text { Principais resultados e } \\
\text { conclusões }\end{array}$ \\
\hline 7. & $\begin{array}{l}\text { GOMES, R. et al. } \\
\text { Informações e valores } \\
\text { de jovens sobre a } \\
\text { Aids: avaliação de } \\
\text { escolares de três } \\
\text { cidades brasileiras. } \\
\text { Ciênc. saúde coletiva, } \\
\text { Rio de Janeiro, v. 10, } \\
\text { n. 2, abr. 2005. }\end{array}$ & $\begin{array}{l}\text { Avaliar as } \\
\text { informaç̃os e os } \\
\text { valores relativos à } \\
\text { AIDS, entre jovens } \\
\text { escolares alvo do } \\
\text { Programa Cuidar, } \\
\text { implantado em três } \\
\text { cidades brasileiras, } \\
\text { no período de } 2000 \\
\text { a } 2001 .\end{array}$ & $\begin{array}{l}\text { - } 0 \text { Programa não teve efeito sobre } 0 \\
\text { nível de informação acerca da AIDS; } \\
\text { nas escolas, sem a intervenção, havia } \\
\text { bem mais informação incorreta (20,6\%) } \\
\text { do que entre os alunos com o programa } \\
(10,9 \%) \text {. } \\
\text { - Houve diferenças entre o nível de } \\
\text { informações entre rapazes e moças; os } \\
\text { depoimentos do grupo de estudo tinham } \\
\text { uma qualidade melhor do que o do grupo } \\
\text { controle. } \\
\text { - Embora não tenha havido um aumento } \\
\text { do acervo de informações dos jovens } \\
\text { escolares, o Programa revelou aspectos } \\
\text { positivos relacionados à capacidade } \\
\text { de reflexão e de argumentação desses } \\
\text { jovens sobre formas de prevenção da } \\
\text { transmissão da AIDS. }\end{array}$ \\
\hline 8. & $\begin{array}{l}\text { TRAJMAN, A. et al. } \\
\text { Knowledge about } \\
\text { STD/AIDS and sexual } \\
\text { behavior among high } \\
\text { school students in } \\
\text { Rio de Janeiro, Brazil. } \\
\text { Cad. Saúde Pública, } \\
\text { Rio de Janeiro, v. 19, } \\
\text { n. 1, fev. 2003. }\end{array}$ & $\begin{array}{l}\text { Avaliar } 0 \\
\text { conhecimento } \\
\text { sobre DST/AIDS e } \\
\text { o comportamento } \\
\text { sexual de alunos } \\
\text { do ensino médio do } \\
\text { Rio de Janeiro, bem } \\
\text { como analisar as } \\
\text { associações com } \\
\text { características } \\
\text { sociodemográficas. }\end{array}$ & $\begin{array}{l}\text { - } 59 \% \text { dos } 945 \text { estudantes de } 13 \text { a } \\
21 \text { anos já haviam iniciado a sua vida } \\
\text { sexual. A mediana de idade da primeira } \\
\text { relação sexual foi de } 15 \text { anos. } \\
\text { - Embora } 94 \% \text { conhecessem a proteção } \\
\text { conferida pelo uso do preservativo, } \\
\text { somente } 34 \% \text { declararam usá-lo } \\
\text { sempre. } \\
\text { - Houve associação entre baixa renda } \\
\text { familiar e conhecimento insatisfatório } \\
\text { e do uso inconstante de preservativos. } \\
\text { Não houve, entretanto, associação } \\
\text { entre conhecimento insatisfatório e uso } \\
\text { inconstante de preservativo. }\end{array}$ \\
\hline
\end{tabular}

\section{DISCUSSÃO}

\section{Caracterização dos artigos}

Verificou-se que os oito artigos em questão são trabalhos originais, o que justifica a realização desta revisão integrativa, como método capaz de reunir e sintetizar o conhecimento produzido sobre a temática estudada. 
Quatro dos artigos incluídos na revisão tiveram sua coleta de dados, análise, submissão ao periódico e/ou publicação realizadas após dezembro 2007, período de instituição do Programa Saúde na Escola. Dessa forma, esses estudos tiveram tempo suficiente para ter pleno conhecimento a respeito da implantação do Programa, bem como apreender a importância que representa a articulação entre as políticas e ações de educação e saúde por ele pregada. Apesar disso, apenas um estudo (MALTA et al., 2011) faz menção ao PSE.

O Programa anterior, o Saúde e Prevenção nas Escolas, também é mencionado apenas por esse mesmo artigo (MALTA et al., 2011), embora sete dos oito estudos selecionados explicitem a realização de suas coletas de dados e/ou submissão ao periódico em períodos posteriores a 2003, ano em que o projeto foi implementado.

Esta constante, mas ainda insuficiente mobilização em torno de políticas públicas voltadas, dentre outras coisas, à abordagem das doenças sexualmente transmissíveis entre os estudantes e a articulação entre os setores saúde e educação, talvez tenha associação direta ao fato de que, "no Brasil, no âmbito do currículo escolar oficial, a Educação Sexual não é uma disciplina obrigatória, mas sim, uma temática a ser transversalizada nos diversos conteúdos” (FURLANI, 2007, p. 272).

No que concerne à formação dos autores, nota-se uma prevalência de médicos, profissional este que está apto a aconselhar, diagnosticar e tratar os casos de DST. Além disso, esse achado mostra o papel de destaque dessa classe como pesquisadora, uma vez que, como ressalta Guimarães (2011), a medicina é a área predominante em quase 20\% dos grupos que realizam pesquisa em saúde no Brasil.

Em seguida, representando quase um terço do total de autores dos estudos analisados, estão os profissionais de enfermagem, o que aponta para o interesse destes em pesquisar aspectos relacionados à sexualidade e sua relação com a saúde pública. Isso reforça o papel do enfermeiro como ator fundamental na articulação entre escolas e unidades de saúde, já que é ele, geralmente, o gerente das unidades e coordenador das ações de educação em saúde.

Todavia, vale ressaltar que a abordagem tratada por esses profissionais, médicos e enfermeiros, ainda é muito mais informativa apenas do ponto de vista biológico e fisiológico, o que sugere a existência de fragilidades de base pedagógica.

Nessa perspectiva, entende-se que os cursos de licenciatura na área da saúde são fundamentais para a construção dessa base. Assinala-se, neste universo, a licenciatura em enfermagem, cujo curso 
forma profissionais voltados também para atuação na educação básica, possuindo ainda especial capacidade para influenciar a sociedade, por meio da possibilidade de rompimento com a valorização da educação progressista e dialética e com a formação voltada para o modelo biologicista, autoritário e normalizador entre os serviços de saúde e a população.

Em meio à diversidade de categorias existentes sobre a temática sexualidade e sexo, entre as quais se inserem as DSTs, pode-se dizer que é pertinente abordar tais temas não apenas nos cursos de licenciatura da área da saúde, mas também na formação profissional dos educadores. Por mais "reservado" que seja o assunto para algumas pessoas, tais assuntos devem ser discutidos, a fim de que se tornem progressivamente mais naturais e compreendidos no seu amplo sentido (biológico, psicológico, social, cultural e espiritual) (JAQUES; PHILBERT; BUENO, 2012).

Apesar da maior prevalência de médicos e enfermeiros, é possível verificar também uma grande gama de formações na autoria dos artigos, inserindo, além dos profissionais das ciências da saúde, aqueles com formação em ciências humanas e exatas. Tal inserção reflete a importância da multi e interdisciplinaridade numa realidade que vise à aproximação da saúde e educação no contexto da formação integral dos estudantes da rede pública de educação básica.

Embora haja apenas um profissional da educação inserido entre a autoria dos estudos analisados, salienta-se que esse fato se deve à maior relação das bases de dados investigadas neste estudo (MEDLINE, LILACS; BDENF), com sua abrangência na esfera da saúde e, consequentemente, entre profissionais desta área. Assim, acredita-se que bases de dados voltadas para a educação - e não contempladas pela BVS - possam abranger uma gama maior de estudos sobre a temática.

Para Frade e Meira (2012), a prática interdisciplinar pode ser vista como um espaço que emerge por meio de interações discursivas, notadamente como linguagem orientada a conteúdos, que são compartilhadas e reguladas pelos participantes (alunos e professores), proporcionando possibilidades para relações passado-presente-futuro nos discursos dos alunos sobre as disciplinas envolvidas, formando, assim, um elo de comunicação entre elas.

Pensa-se no professor como peça fundamental no âmbito da saúde escolar, pois ele será o responsável por dar continuidade ao trabalho proposto, além de ser conhecedor da individualidade dos alunos e da territorialidade do seu contexto de ensino. 
Logo, para a construção do saber na escola, faz-se necessária a formação continuada e permanente do docente, além de despertar seu envolvimento na ação educativa, pois organizar e estimular esse aprendizado, além de ser fator favorável a uma vida saudável, é também um pressuposto ético e de cidadania.

Os resultados mostraram, em relação à titulação dos autores, uma maioria de pós-graduados, prevalecendo os doutores. Tal fato corrobora com o papel que estes apresentam como componente essencial na base do trabalho de pesquisa. Guimarães (2011) ressalta que se, por um lado, a curva do número de egressos de doutorados nas duas últimas décadas é bastante satisfatória, por outro, o Brasil ainda carece de estímulos para estágios pós-doutorais.

Percebeu-se ainda a presença de graduandos entre a autoria dos estudos revisados, ressaltando a importância de se iniciar a formação do pesquisador ainda durante o curso de graduação. Uma vez que este aluno tenha participado do processo de pesquisa ainda como graduando e se interessado em ingressar no mestrado, estaria levando consigo experiência teórica e prática que o ajudaria no desenvolvimento de suas atividades na pós-graduação (PARDO; COLNAGO, 2011).

A maioria das produções analisadas foi desenvolvida por autores da região Sudeste, representada por pesquisadores vinculados a instituições de ensino superior do Rio de Janeiro e de São Paulo, que representam mais da metade do corpo total de autores dos artigos selecionados. Em seguida, estão os pesquisadores do Nordeste e do Centro-Oeste, respectivamente. Não houve representantes das regiões Norte e Sul do país. Este achado corrobora parcialmente o que foi verificado por Guimarães (2011), que, entre os anos de 2000 a 2008, identificou que a distribuição geográfica das atividades de pesquisa em saúde acompanhou o padrão de concentração regional, sendo que 63\% dos grupos de pesquisa estão localizados na região Sudeste, 17\% no Sul, $13 \%$ no Nordeste, $5 \%$ no Centro-Oeste e $2 \%$ no Norte.

\section{Abordagens temáticas dos artigos}

Os estudos permitiram identificar os conhecimentos e comportamentos relacionados às DSTs entre os adolescentes escolares brasileiros nos últimos anos, bem como a participação da escola na promoção da saúde sexual desses indivíduos. Primeiramente, destaca-se o início da vida sexual cada vez mais cedo, principalmente entre os adolescentes do sexo masculino (TRAJMAN et al., 2003; MALTA et al., 2009). 
Essa questão é preocupante, pois se associa ao não uso ou uso inadequado de preservativos e suas consequências: gravidez precoce e infecção por DST/AIDS (MALTA et al., 2009; DIAS et al., 2010). Isso demonstra uma prática educacional informativa ineficiente ou deficitária, pois, embora muito se aborde sobre DST/AIDS, ainda se observa um conhecimento precário, principalmente relacionado aos aspectos biológicos e forma de contágio.

As pesquisas selecionadas apontam que o conhecimento sobre DST/AIDS, em geral, apresenta-se insatisfatório, o que inclui a persistência de conceitos equivocados quanto às formas de transmissão dessas doenças e aos comportamentos de risco, a exemplo da crença na transmissão do vírus do HIV pelo uso de banheiro público, beijo, abraço e picada de inseto (ROMERO et al., 2007; FERNANDES et al., 2009; DIAS et al., 2010; COELHO et al., 2011).

Excetuando-se a AIDS, os estudos trazem ainda níveis baixos de conhecimentos em relação a outras DSTs não muito discutidas nas escolas, como gonorreia, sífilis e clamídia. Trata-se de uma informação preocupante, pois, como citado, as tendências apontam para a população adolescente e de adultos jovens sendo responsável por até $25 \%$ de todos os casos diagnosticados para algumas DSTs (BRASIL, 2006a). É importante considerar ainda que quando os jovens dizem "conhecer uma doença", pode significar simplesmente ter ouvido falar dela e, muitas vezes, de forma vaga, o que se subentende como desconhecimento do assunto (ROMERO et al., 2007).

A iniciação sexual precoce e a não absorção das informações discutidas podem ser apontadas como consequência de inúmeros fatores que influenciam no comportamento sexual desses indivíduos: classe social, gênero, raça-cor e escolaridade seriam as mais relevantes. Percepções, valores, crenças, sentimentos e conhecimentos de cada indivíduo também devem ser considerados, pois refletem em seus pensamentos e práticas de vida (TRAJMAN et al., 2003; MALTA et al., 2009; DIAS et al., 2010). Dessa forma, o modelo familiar possui uma relevante função, pois uma família unida, onde estão presentes amor, respeito, compromisso, ensinamentos e limites, funciona como fator protetor para comportamentos de riscos dos adolescentes (ROMERO et al., 2007).

Alguns autores defendem a ideia de que tanto os pais como os educadores devem evitar a discussão sobre a temática DST/AIDS e sexualidade de maneira geral, por acreditar que haja um estímulo à atividade sexual entre os adolescentes. Entretanto, alguns estudos, como o realizado pelo Centro Brasileiro de Análise e 
Planejamento (CEBRAP) e o de Andrade et al. (2009), evidenciaram que as informações a respeito das DST/AIDS não estimulam práticas sexuais nem abstinência, mas sim o comportamento sexual responsável. Desse modo, não há nenhuma evidência que suporte o pensamento de evitar a discussão sobre DST/AIDS (ROMERO et al., 2007; COELHO et al., 2011).

Apesar de significativas falhas na educação em saúde sexual do escolar, a escola foi apontada como um dos principais meios de acesso a informações sobre DST/AIDS. Além disso, a figura do professor é relacionada a um valor simbólico significativo (FERNANDES et al., 2009; COELHO et al., 2011).

Entende-se a relevância e necessidade do desenvolvimento de projetos como o Saúde e Prevenção nas Escolas. Aliado a esse projeto, a criação do PSE em 2007, faz com que a discussão sobre a temática sexualidade entre adolescentes potencialize-se e, desse modo, a expectativa de se alcançar os objetivos de promoção de práticas sexuais mais seguras e redução das vulnerabilidades às DSTs, característicos do SPE, sejam fortalecidos.

Entretanto, alguns dos estudos selecionados sugerem a preocupante informação de despreparo dos professores para trabalhos educativos com a temática, seja por desconhecimento do assunto e/ou por influência particular de culturas e modos de agir e pensar. No estudo de Fernandes et al. (2009), professores de alunos deficientes auditivos reconhecem essa lacuna e citam a falta de tempo, de condições e de preparo como os responsáveis por não trabalhar o tema com seus alunos. Resultado semelhante ao encontrado por Pinheiro Filho et al. (2010), ao perceber que significativa parcela dessa população não possui informações suficientes para garantir um comportamento sexual seguro que evite a infecção por DSTs. Por essa razão, menciona-se a necessidade de um profissional de saúde para esclarecimento de dúvidas e apresentação de palestras com uso de material apropriado.

Assim, buscando umainterligação entre a saúde e os educadores de base, destaca-se a importância da inserção do profissional da área de saúde na formação continuada dos professores, no intuito de despertar em seus alunos e na comunidade, de modo geral, por meio da educação em saúde, o interesse pela saúde coletiva.

Além da escola, a mídia (televisão, rádio, revistas, jornais, internet) é atualmente uma importante fonte de informação, embora os artigos analisados sublinhem que é preocupante o valor atribuído a esses veículos de comunicação em massa, pois não são os meios mais 
adequados para promover esclarecimento suficiente sobre temas como DST e AIDS. Ao contrário, as formas utilizadas pela mídia podem causar mais confusão do que esclarecimentos (TRAJMAN et al., 2003; GOMES et al., 2005; COELHO et al., 2011).

Sabe-se que apenas a difusão do conhecimento sobre as formas de transmissão e prevenção às DSTs não são suficientes para alterar significativamente comportamentos de risco, ou seja, nem sempre os conhecimentos podem ser traduzidos em ações. Todavia, as estratégias de educação em saúde nas escolas não devem ser negligenciadas, pois são entendidas como os primeiros passos para percepções corretas e reflexões sobre a temática. Logo, é fundamental a presença de professores devidamente capacitados e preparados para o trabalho com um assunto tão relevante e presente na vida de todos (COELHO et al., 2011).

Portanto, entende-se que as ações de educação em saúde sexual, voltadas para a prevenção de DST/AIDS, são extremamente relevantes, e a escola adquire uma importância especial na construção do conhecimento e estímulo ao comportamento seguro, pois promove a troca de experiências, tomada de decisões e interfere diretamente nos comportamentos de saúde e doença de jovens escolares (MAHEIRIE et al., 2005).

No planejamento dessas ações, é importante que a escola preocupe-se não apenas em transmitir o conhecimento, mas principalmente em fazer reforços periódicos dos ensinamentos, pois, muitas vezes, os adolescentes não se preocupam com as questões de prevenção (ROMERO et al., 2007). Destarte, é fundamental que estes aprendam a identificar situações de risco, compreender vulnerabilidades, conhecer alternativas de proteção e assim se conscientizar dos riscos e dimensões das suas consequências.

\section{CONSIDERACִÕES FINAIS}

Conclui-se, após a elaboração deste estudo, que o tema DST encontra-se bastante difundido e discutido no âmbito escolar, porém o seu entendimento, principalmente no que concerne à transmissão e contaminação, permanece pouco esclarecido para os jovens. Essas concepções errôneas devem ser a todo tempo combatidas, evitando exposição a fatores de risco julgados inofensivos de forma equivocada.

A escola, como principal meio de construção do conhecimento, tem o dever de orientar e direcionar os alunos para uma prática preventiva, por meio de programas educacionais e de abordagem correta, num 
diálogo que deve instigar o adolescente a aprender e prevenir-se por meio de atividades interativas e com profissionais competentes.

O SPE e o PSE surgem com extrema importância pelo caráter informativo e educativo na formação de base dos adolescentes. Esses programas se apresentam não apenas com a capacidade de instruir o aluno, mas de capacitar e envolver os professores e profissionais de saúde de forma direta na saúde escolar, de modo que o conhecimento dos jovens seja transformado em ação.

Essas práticas devem despertar o aluno para uma reflexão crítica, onde de instruído ele passará a ser instrutor em seu meio, criando uma rede de comunicação e responsabilidade mútua entre seu grupo etário. Com essa educação, o jovem passará a praticar um sexo seguro e responsável, expondo a necessidade dos cuidados pessoais e interpessoais, auxiliando na quebra de tabu entre parceiros quanto ao uso de preservativos.

Ressalta-se que a educação escolar nos últimos anos serviu como pilar para o fomento da saúde desta população. Foi possível verificar que o conhecimento sobre DST nas escolas tem uma linha ascendente, embora ainda se tenha muito que melhorar, principalmente no aspecto de acesso universal dessa informação nas escolas. Dessa forma, projeta-se que o número de indivíduos infectados por DSTs apresentem uma tendência de declínio, pois, sendo passíveis de prevenção, atos educativos refletem resultados diretos.

Para isso, é necessário que os educadores vençam suas barreiras pessoais em relação à sexualidade e desfaçam seus pudores e receios ao tratar do tema, não se limitando a uma abordagem superficial. A capacitação destinada aos professores não deve se resumir apenas ao caráter de conhecimento teórico, mas também no ato de relacionar-se e fazer-se compreender.

Sabe-se, no entanto, que tal exigência esbarra em determinados aspectos, sobretudo no que diz respeito à formação universitária do profissional da educação, uma vez que, diferentemente do ensino escolar, as universidades são dotadas de maior autonomia, inclusive no que se refere ao conhecimento. Assim, se por um lado ela garante que professores sensíveis à temática das DSTs abordem tais questões em suas disciplinas, por outro também possibilita que um número não desprezível de professores e outros profissionais concluam a formação superior sem que esses temas tenham sido contemplados (ALTMANN, 2013).

Comolimitação do estudo, pode-se citar a quantidade reduzida de artigos encontrados que abordassem o assunto e, sobretudo, 
a opção por pesquisar apenas em bases de dados contidas na BVS. Esta, por se tratar de um banco de dados da área da saúde, apresenta, na maioria dos casos, publicações de profissionais desse segmento, ao passo que profissionais da área de educação, mais uma fonte de informação no presente estudo, buscam direcionar suas publicações a periódicos indexados em outras bases. Vale ressaltar, no entanto, que os achados encontrados e discutidos neste artigo servem de base para análise da atual situação da saúde escolar e incremento para realização de estudos futuros.

Sugere-se, então, que novos estudos sejam realizados, se possível com o acréscimo de busca a bases de dados que contemplem uma maior gama de publicações da área educacional, ampliando os horizontes e discussões a respeito do tema, além de observar a eficiência na nova abordagem da saúde escolar, a partir da efetivação de redes de atenção de base. Espera-se ainda que esses estudos verifiquem os avanços e as lacunas existentes, para que, dessa forma, possam consolidar uma saúde escolar preventiva, promotora, eficaz e eficiente.

\section{REFERÊNCIAS}

ALTMANN, H. Diversidade sexual e educação: desafios para a formação docente. Sex., Salud Soc. (Rio J.), Rio de Janeiro, n. 13, p. 69-82, abr. 2013.

ANDRADE, H. H. S. M. et al. Changes in sexual behavior following a sex education program in Brazilian public schools. Cad. Saúde Pública, Rio de Janeiro, v. 25, n. 5, maio 2009.

BRASIL. Decreto n ${ }^{\circ}$ 6.286, de 5 de dezembro de 2007. Institui o Programa Saúde na EscolaPSE, e dá outras providências. 2007. Disponível em: < http://www.planalto.gov.br/ccivil_03/_ ato2007-2010/2007/decreto/d6286.htm> Acesso em: 19 mar. 2013.

BRASIL. Ministério da Saúde. Secretaria de Atenção à Saúde. Departamento de Ações Programáticas Estratégicas. Marco teórico e referencial: saúde sexual e saúde reprodutiva de adolescentes e jovens. Brasília: Ministério da Saúde, 2006a. (Série B. Textos Básicos de Saúde).

BRASIL. Ministério da Saúde. Secretaria de Vigilância em Saúde. Boletim Epidemiológico Aids • DST - 2012: versão preliminar. Brasília: Ministério da Saúde, 2012.

BRASIL. Ministério da Saúde. Secretaria de Vigilância em Saúde. Programa Nacional de DST e Aids. Manual de Controle das Doenças Sexualmente Transmissíveis. Brasília: Ministério da Saúde, 2006b. (Série Manuais n. ${ }^{\circ}$ 68. 4. Ed.).

COELHO, R. F. S. et al. Conhecimentos e crenças sobre doenças sexualmente transmissíveis e HIV/AIDS entre adolescentes e jovens de escolas públicas estaduais da região oeste de Goiânia. Rev. Patol. Trop., Goiânia, v. 40, n. 1, jan.-mar. 2011.

DEHNE, K. L.; RIEDNER, G. R. Sexually transmitted infections among adolescents: the need for adequate health services. Geneva: World Health Organization; 2005. 
DIAS, F. L. A. et al. Riscos e vulnerabilidades relacionados à sexualidade na adolescência. Rev. enferm. UERJ, Rio de Janeiro, v. 18, n. 3, jul.-set. 2010.

FERNANDES, J. F. P. et al. Conhecimento de alunos deficientes auditivos e de seus educadores relacionado às doenças sexualmente transmissíveis. Rev. enferm. UERJ, Rio de Janeiro, v. 17, n. 3, jul.-set. 2009.

FRADE, C.; MEIRA, L. Interdisciplinaridade na escola: subsídios para uma Zona de Desenvolvimento Proximal como espaço simbólico. Educ. rev., Belo Horizonte, v. 28, n. 1, mar. 2012.

FURLANI, J. Sexos, sexualidades e gêneros: monstruosidades no currículo da Educação Sexual. Educ. rev., Belo Horizonte, n. 46, dez. 2007.

GOMES, R. et al. Informações e valores de jovens sobre a Aids: avaliação de escolares de três cidades brasileiras. Ciênc. saúde coletiva, Rio de Janeiro, v. 10, n. 2, abr. 2005.

GUIMARÃES, R. Desafios da pós-graduação em saúde humana no Brasil. Rev. Saúde Pública, São Paulo, v. 45, n. 1, fev. 2011.

JAQUES, A. E.; PHILBERT, L. A. S.; BUENO, S. M. V. Significados sobre sexualidade humana junto aos professores do ensino fundamental. Arq. Ciênc. Saúde UNIPAR, Umuarama, v. 16, n. 1, p. 45-50, jan.-abr. 2012.

LOURO, G. L. Gênero e sexualidade: pedagogias contemporâneas. Pro-Posições, Campinas, v. 19, n. 2, maio-ago. 2008.

MAHEIRIE, K. et al. Oficinas sobre sexualidade com adolescentes: um relato de experiência. Psicol. estud., Maringá, v. 10, n. 3, dez. 2005.

MALTA, D. C. et al. Orientações de saúde reprodutiva recebidas na escola - uma análise da Pesquisa Nacional de Saúde do Escolar nas capitais brasileiras e no Distrito Federal, 2009. Epidemiol. Serv. Saúde, Brasília, v. 20, n. 4, dez. 2011.

MARTINS, L. B. M. et al. Fatores associados ao uso de preservativo masculino e ao conhecimento sobre DST/AIDS em adolescentes de escolas públicas e privadas do Município de São Paulo, Brasil. Cad. Saúde Pública, Rio de Janeiro, v. 22, n. 2, fev. 2006.

MENDES, K. D. S.; SILVEIRA, R. C. C. P.; GALVÃO, C. M. Revisão integrativa: método de pesquisa para a incorporação de evidências na saúde e na enfermagem. Texto contextoenferm, v. 17, n. 4, out.-dez. 2008.

PAIVA, V. A psicologia redescobrirá a sexualidade? Psicol. estud., Maringá, v. 13, n. 4, p. 641651, out.-dez. 2008.

PARDO, M. B. L.; COLNAGO, N. A. S. Formação do pesquisador: resultados de cursos de pós-graduação em educação. Paidéia (Ribeirão Preto), Ribeirão Preto, v. 21, n. 49, ago. 2011.

PINHEIRO FILHO, T. R. C. et al. Análise do conhecimento sobre DSTs e planejamento familiar entre deficientes auditivos e ouvintes de uma escola pública de Fortaleza. Rev. bras. educ. espec., Marília, v. 16, n. 1, abr. 2010.

ROMERO, K. T. et al. O conhecimento das adolescentes sobre questões relacionadas ao sexo. Rev. Assoc. Med. Bras., São Paulo, v. 53, n. 1, fev. 2007.

TRAJMAN, A. et al. Knowledge about STD/AIDS and sexual behavior among high school students in Rio de Janeiro, Brazil. Cad. Saúde Pública, Rio de Janeiro, v. 19, n. 1, fev. 2003.

WORLD HEALTH ORGANIZATION (WHO). Sexually transmitted and other reproductive tract infections: a guide to essential practice. Geneva: World Health Organization, 2005. 
Recebido: 11/06/2013 Aprovado: 20/06/2014

Contato:

Universidade Estadual do Sudoeste da Bahia Campus de Jequié / Departamento de Saúde Avenida José Moreira Sobrinho, s/n - Jequiezinho Jequié | BA | Brasil CEP 45.206-190 